\title{
BEING A C-STUDENT IS THE NEW NORMAL: A LITERATURE REVIEW ON GRADES, SELF-WORTH, AND MENTAL WELLBEING
}

\author{
Agnes G. d'Entremont ${ }^{1}$, Juan C. Abelló ${ }^{1}$,Eisha Sharda ${ }^{2}$ \\ ${ }^{l}$ Department of Mechanical Engineering, ${ }^{2}$ Department of Psychology, University of British Columbia \\ agnes.dentremont@mech.ubc.ca, abello@mech.ubc.ca
}

\begin{abstract}
The competitive application process for many Canadian engineering schools can lead to enrolling cohorts of students where nearly everyone is accustomed to having above average grades. Anecdotally, instructors frequently observe a difficult transition to earning average or below average grades. This may be due to students strongly basing their sense of personal worth on academic performance. Declines or variability in selfworth or self-esteem can impact mental wellbeing.

Given the widely reported prevalence of mental health concerns and counselling usage at Canadian universities, we chose to explore the connections between receiving lower than expected grades, self-worth and mental wellbeing as well as possible interventions that instructors could employ to help students manage this transition.
\end{abstract}

Keywords: Grades, Self-worth, Self-esteem, Stress, Anxiety, Mental health, Mental wellbeing, Depression, Academic performance, Academic disappointment

\section{INTRODUCTION}

Students who attend Canadian engineering programs have often received high marks throughout their elementary and secondary schooling. This is partially due to the limited seats and competitive application process in many Canadian engineering institutions, leading to relatively high cut-off and average incoming grades. (For example, the average score of incoming first-year students to the UBC Faculty of Applied Science is 93\% [1].) At a number of schools, there are also competitive applications into highly-sought-after second-year programs, such that a second-year class may comprise primarily of students who achieved high marks in first year. In each case, there may be an entire class of students who are accustomed to earning above-average grades. By definition, half of them will now be below average, with some receiving marks in the $60 \mathrm{~s}$ and $70 \mathrm{~s}$ for the first time. Anecdotally, engineering instructors note that this sudden and substantial change in marks is associated with student stress and other negative emotions.

In this paper, we review literature around the connections between academic disappointment, selfesteem (or self-worth), self-concept, and mental wellbeing, with an application to the Canadian engineering context. We also explore the larger question of what we can do to help our students. (A list of psychology terms relevant to and used in this paper appears in Table 1.)

Table 1: Terminology definitions

\begin{tabular}{|l|l|}
\hline Academic disappointment & $\begin{array}{l}\text { The feeling of failure due to a lower-than-expected grade, which may still be a passing } \\
\text { grade [2] }\end{array}$ \\
\hline Self-esteem (or self-worth) & $\begin{array}{l}\text { The confidence (positive or negative) in one's ability and the value one attributes to } \\
\text { oneself [3] }\end{array}$ \\
\hline Self-concept & One's perception (thoughts and feelings) about oneself [4] \\
\hline Mental wellbeing & The ability to work to one's full potential with an adaptive nature to stress [5] \\
\hline Self-determination & $\begin{array}{l}\text { The process through which one controls one's life by internal processes rather than by } \\
\text { external factors [6] }\end{array}$ \\
\hline Self-regulation & The ability to maintain one's emotions and behaviours in response to adverse events [7] \\
\hline Autonomous behaviours & $\begin{array}{l}\text { Behaviours that are perceived to be internal and completed out of importance and/or } \\
\text { interest to the self [8] }\end{array}$ \\
\hline Controlled behaviours & $\begin{array}{l}\text { Behaviours that are perceived as external to the self and coerced through social, } \\
\text { relational, or intrapsychic occurrences [8] }\end{array}$ \\
\hline
\end{tabular}




\section{GRADES, SELF-ESTEEM AND MENTAL WELLBEING}

The pursuit of self-esteem involves behaviours intended to prove to ourselves and others that we meet certain criteria of worth [9]. Crocker and Wolfe refer to these criteria as contingencies of self-worth [10]. These contingencies may be internal, such as virtue or religious faith, or external, such as the approval from others or scoring a higher grade than one's peers [11]. Studies made on first-year undergraduate students indicate that external contingencies predicted social-, academic- and aggression-related problems [11].

\subsection{Grades and Self-Esteem}

Students experience a drop in self-esteem when they receive low marks [12]. The decrease in self-esteem is greater for students who define their sense of worth based on academic performance [13]. More than $80 \%$ of firstyear undergraduate students (all majors) define their selfworth in terms of academic performance, and $65 \%$ define it based on how they do when compared to their peers [11], [14]. These students interpret academic disappointment as indicating they have low worth as humans [7], [12].

Basing self-esteem on grades may affect learning. Crocker proposes that the pursuit of self-esteem brings longer-term costs to competency [11], which can be defined as the ability a person has to master or change their surroundings [15]. The level of competency that someone develops depends on their willingness to learn from their failures [11]. Students who define their selfesteem on grades and perform below their expectations may avoid feedback about their perceived failure [11]. This prevents them from learning from the experience and thus improving their competency and grades.

\subsection{Self-Esteem and Mental Wellbeing}

The links between self-esteem and mental wellbeing are complex. While the relationship between level of selfesteem and psychological functioning has inconsistent evidence, Kernis suggests that stability of self-esteem may be more directly related to wellbeing than level of self-esteem [16], with unstable self-esteem being linked to depressive disorders [17]. Roberts and Monroe found links between the instability of an undergraduate student's self-esteem and increased depressive symptoms when faced with academic stress (preparing for, writing, and receiving grades for exams) [2]. Undergraduate students who based their self-esteem on external contingencies, such as academics, tend to have a higher degree of instability in their self-esteem [11]. This makes them at higher risk for depression [17], [18].

Crocker suggests that the pursuit of self-esteem involves a longer-term cost to relatedness [11]. Studies show that people respond to events that threaten their self- esteem with "avoidance, distancing, and withdrawal, or with blame, excuses, anger, antagonism, and aggression" [19]. These behaviours damage relationships, increase isolation, and take a toll on others [11]. This is troublesome because our engineering programs expect students to function in teams (Canadian Engineering Accreditation Board Graduate Attribute 6 [20]) and we often encourage students to study together when solving assignments or preparing for tests.

As with the case of competency, relatedness and grades have a cyclic relationship. Students whose selfesteem decrease after receiving low grades may exhibit behaviours that damage their relationships with their peers in study or project groups, thus increasing the likelihood of poor performance in academic team pursuits.

\section{ACADEMIC STRESS AND MENTAL HEALTH}

There is a growing awareness of the prevalence of mental health concerns and counselling usage at Canadian universities. Thirty-one percent of students surveyed across the country reported that mental health issues were interfering with their ability to perform [21]. Many schools, particularly those in smaller towns, struggle with the financial and logistical challenges involved in providing increased access to mental health services for students [21].

\subsection{Undergraduate Student Wellness Surveys}

Universities and related organizations have recently been exploring the state of student mental wellbeing, to better outline the issues facing post-secondary students. In 2011, an institution-wide survey at Queen's University found that $60 \%$ of students reported above average or "tremendous" stress levels, and $62 \%$ of all students reported that consequences of this stress for them included mental health problems. The largest reported source of stress was academic pressures (73\%) [22].

The McGill University Engineering Undergraduate Society completed a survey of engineering undergraduate students in late 2016. Seventy-four percent of respondents said that the high workload was the most stressful part of the program. Most of them indicated they had felt overwhelmed (87\%) and exhausted (not due to physical activity, $85 \%$ ) in the prior 12 months, with half or more reporting feeling very sad (57\%), overwhelming anxiety $(55 \%)$, very lonely $(54 \%)$, and hopeless $(50 \%)$ [23]. Fifteen percent reported having used campus counselling and mental health services, with $69 \%$ reporting a lack of time to prioritize self-care as a reason for not seeking on-campus help [23]. As a point of reference, parts of the clinical definition of major depressive disorder include feeling sad, hopeless, 
overwhelmed, and lacking in energy for a period of at least two weeks [24].

The UBC Engineering Undergraduate Society also completed a survey on student wellness in late 2017, the results of which are being presented at this conference. The authors found a high prevalence of "frequent or constant stress" (83\% during exams, $47 \%$ at other times during the semester) among respondents [25].

In the 2016 Undergraduate Experience Survey, 64\% of UBC engineering student respondents self-reported experiencing anxiety, stress and/or depression that affected their academics (received lower grade, dropped or did not complete course, or experienced significant disruption of studies), and another $31 \%$ reported experiencing anxiety, stress and/or depression without an academic impact [26].

With increasing use of counselling services and the data-supported worries around student mental health, the effect of grade pressures and perceptions may be an area of concern.

\subsection{General Resiliency}

While engineering programs have traditionally been competitive, and past students typically encountered some grade "sticker shock" upon entry, there is a sense that current students are more frail when reacting to adversity than former generations [27]. However, Rosenbaum and Weatherford argue that larger cultural shifts may be partly responsible. For example, belief about a recent scarcity of long-term, well-paid, full-time jobs, and a resulting hypercompetitive employment realm upon graduation, may make every poor mark appear ruinous to future stability [27]. One could argue that this is entirely rational based on students' past experience - a single failed course could have derailed their plans to gain admittance to engineering school at some institutions, as competition for first-year seats is intense and admission mark cut-offs are high [28].

Rosenbaum and Weatherford also suggest that a greater emphasis on and openness around mental health may encourage current students to seek help when past students were tacitly dissuaded from doing so, which could be misconstrued as lack of toughness or determination [27]. In fact, when McGill engineering students were asked about why they did not use campus resources, only $18 \%$ reported it was due to stigma around mental health [23].

\section{POTENTIAL INTERVENTIONS}

It appears that the combination of student grade expectations and self-concept heavily tied to academic achievement colliding with highly selective admissions, demanding programs and larger societal changes may be contributing to overwork, stress and mental health concerns within Canadian engineering undergraduate programs. We wanted to know what educators might be able to do to improve this situation.

\subsection{Supporting Student Autonomy}

Self-determination theory differentiates between human motivations, specifically autonomous (selfdetermined) and controlled reasons for doing something [29]. That is, doing something because it is enjoyable or interesting, or the outcome is personally satisfying (intrinsic motivation), versus doing something because one is told to, or because one would feel guilty if one did not (controlled motivation) [8]. There is evidence that higher levels of student feelings of autonomy can benefit both academic performance and anxiety in post-secondary courses.

Vansteenkiste et. al. found that when a learning activity was framed with intrinsic goals and in an autonomy-supportive way (e.g. suggesting that completing the activity was a good idea because it could ultimately help the community, rather than telling students to do it because it could save them money), there was a positive effect on outcomes like test performance and persistence [30]. Their findings suggest that the integration of intrinsic goals into learning activities and the creation of learning environments that support autonomy can foster dedication to and engagement in the material [30]. An intervention based on this work could be adapted by engineering instructors to promote course commitment and subsequently enhance performance [30].

Black and Deci found in an organic chemistry course that "students' reports of entering the course for relatively autonomous (vs. controlled) reasons predicted higher perceived competence and interest/enjoyment and lower anxiety and grade-focused performance goals during the course" [8]. This is an interesting finding in the context of engineering, where most first- and second-year courses are mandatory (students do not have autonomy in selecting their courses). While having many mandatory courses is unlikely to change, it may be possible to actively compensate for this. Black and Deci also found that instructor support of autonomy increased perceived competence and enjoyment of the course, and reduced anxiety over the semester [8]. Hall and Webb found similar results in an introductory physics course: when students perceived instructors to be autonomy-supporting, they had less anxiety about taking the course [29]. Similar to Black and Deci, they found that autonomous reasons for learning the material were correlated with student performance, and they also found that instructor autonomy-support could increase how autonomous the students' reasons were for studying the material over the term (i.e. they increasingly wanted to study it, rather than feeling forced to study it) [29]. That is, even in a required course, engineering instructors may be able to reduce student anxiety by supporting student autonomy [29]. 
Work by Reeve and Jang examines how instructors can support (or thwart) student autonomy [31]. Instructors can help students find the alignment between classroom activities and their intrinsic motivation for learning. At the other end of the spectrum, instructors could impose external goals and require adherence to their agendas. The autonomy-supportive behaviours found include the following:

- Higher total time the instructor spent listening

- Higher total time spent allowing students to work in their own way

- Higher total time the students spent talking

- Praise as informational feedback (e.g. "Good job")

- Offering encouragement (e.g. "Keep going, you're close")

- Offering hints (e.g. "It might be easier if you ...", "X might work better than Y")

- Being responsive to student-generated questions (e.g. "Yes, that's a good point")

- Making perspective-acknowledging statements (e.g. "This is a challenging one") [31]

They also found the following to reduce student perceptions of autonomy:

- Higher total time holding/monopolizing learning materials (e.g. demonstrating further when students could otherwise start an activity)

- Exhibiting solutions/answers (physically showing a solution before the student had time to find it themselves)

- Uttering solutions/answers (describing a solution before the student had time to find it themselves)

- Uttering directives/commands (e.g. "Do it this way")

- Making should/got to statements (e.g. "You should ..., "You ought to ...")

- Asking controlling questions (e.g. "Can you do what I showed you?") [31]

Engineering instructors can work to adopt autonomysupportive behaviours in their courses.

\subsection{Peer and Social Support}

There is some evidence that social supports may lead to increased self-esteem for engineering students whose self-definition (including self-esteem) is based on close relationships [32]. These social supports could be encouraged by educators through officially sponsoring student organizations and encouraging students to participate in peer social events. Friedlander et. al. also found that increased social support from peers predicted better adjustment to university [33]. This finding could be extended by engineering intructors and facilitation of peer relations could be addressed in the classroom through group activities and peer-based work [32].

\subsection{Persistence and Focus}

Thayer suggests that students who receive lower grades on their first exam are significantly more likely to drop out than other students [34]. However, students who receive low grades but did not drop out continue to do better on a second exam in the course [34]. This suggests that interventions by engineering instructors to decrease drop-out rates may allow students to improve later in the course. Improved grades may have additional effects on increasing self-esteem and mental wellness. (Also, persisting in the course may allow instructors to positively influence students' feelings of autonomy, as discussed above) [34].

For individuals that have low self-esteem, instructions to focus on the task at hand can improve performance when compared to no manipulation to the situation and task completion in the presence of an audience [35]. Brockner and Hulton showed that instructions which emphasize the need for undivided attention to a task and highlight that the task may be tricky improve the performance of individuals with low self-esteem [35]. This can be applied to engineering students through task emphasis by engineering insructors. To reduce the selfdoubt possessed by low self-esteem students, activities with instructions that encourage focus and reiterate the difficulty of the task could be implemented [35].

\section{DISCUSSION}

In this review of literature, we found that academic stress is widely experienced by undergraduate students in Canada, and that grade expectations may be related to this lack of mental wellbeing. Grade expectations and selfconcept around grades or academic achievement are connected for some students. Academic disappointment can influence self-worth/self-esteem, and instability of self-esteem has been associated with depressive symptoms when faced with academic stress.

Canadian students report high levels of stress, high workloads and a high prevalence of feelings of hopelessness, sadness, and being overwhelmingly anxious. The larger social and structural causes are unclear, although we can suspect high admission standards (those who enroll in engineering have needed to maintain a fairly flawless academic record in order to be admitted), high credit loads (associated with being a professional program and accreditation requirements), and a job market that increasingly provides less secure employment. These possible causes are challenging-toimpossible for instructors to address, however we may influence what occurs in our classrooms and programs.

Increased feelings of autonomy seem to positively influence many of the factors we have been discussing reducing anxiety, increasing self-esteem, and increasing academic performance. Instructors can influence feelings of autonomy, even in mandatory courses. We can 
champion measures to strengthen social supports for students. And we can help students focus and persist.

On a larger scale, helping students find more time for self-care and making counselling easier to access are larger goals we can aim for within our institutions.

\section{CONCLUSIONS}

Grade pressures may have significant impacts on undergraduate engineering students in terms of mental health and wellbeing. Grade pressures may be accompanied by feelings of declined self-worth/selfesteem and ultimately, reduced academic performance. Given the detrimental effects of declines in mental health and wellbeing, there are several possible interventions that can implemented at the level of the instructor, program, and/or institution. Of these, fostering an autonomy-friendly environment, increasing peer and social support and implementation of task-oriented work are discussed. Future directions could include the implementation of the possible interventions in the classroom setting and/or additional evaluation of student needs in engineering courses.

\section{Acknowledgements}

We would like to thank Ms. Amy Vozel, Engineering Student Services, UBC, for providing support to this project.

\section{References}

[1] B. Ramsay, "UBC admission stats 2016/17: Averages, acceptance rates and more," The Ubyssey, 2017. [Online]. Available: https://www.ubyssey.ca/blog/ubcadmission-stats-2016-averages-acceptance-rates-andalso-baileys-legacy/. [Accessed: 20-Jan-2018].

[2] J. E. Roberts and S. M. Monroe, "Vulnerable SelfEsteem and Depressive Symptoms: Prospective Findings Comparing Three Alternative Conceptualizations," J. Pers. Soc. Psychol., vol. 62, no. 5, pp. 804-812, 1992.

[3] T. L. Eromo, "The rise, fall, and resurgence of "selfesteem': A critique, reconceptualization, and recommendations.," N. Am. J. Psychol., vol. 19, no. 2, pp. 255-302, Jan. 6AD.

[4] M. Bong and E. M. Skaalvik, "Academic Self-Concept and Self-Efficacy: How Different Are They Really? Author ( $\mathrm{s}$ ): Mimi Bong and Einar M . Skaalvik Published by: Springer JSTOR is a not-for-profit service that helps scholars, researchers, and students discover , use , and build," vol. 15, no. 1, pp. 1-40, 2014.

[5] T. Rose, S. Joe, A. Williams, R. Harris, G. Betz, and S. Stewart-Brown, "Measuring Mental Wellbeing Among Adolescents: A Systematic Review of Instruments," J. Child Fam. Stud., vol. 26, pp. 2349-2362, 2017.
[6] M. L. Wehmeyer, K. A. Shogren, T. D. Little, and S. J. Lopez, "Introduction to the Self-Determination Construct," in Development of Self- Determination Through the Life-Course, M. L. Wehmeyer, K. A. Shogren, T. D. Little, and S. J. Lopez, Eds. Springer, 2017, pp. 3-16.

[7] J. Crocker, A. T. Brook, Y. Niiya, and M. Villacorta, "The pursuit of self-esteem: Contingencies of selfworth and self-regulation," J. Pers., vol. 74, no. 6, pp. 1749-1771, 2006.

[8] A. E. Black and E. L. Deci, "The effects of instructors' autonomy support and students' autonomous motivation on learning organic chemistry: A selfdetermination theory perspective," Sci. Educ., vol. 84, no. 6, pp. 740-756, 2000.

[9] W. James, F. Burkhardt, F. Bowers, and I. K. Skrupskelis, The principles of psychology. Harvard University Press, 1981.

[10] J. Crocker and C. T. Wolfe, "Contingencies of selfworth.," Psychol. Rev., vol. 108, no. 3, pp. 593-623, Jul. 2001.

[11] J. Crocker, "The costs of seeking self-esteem.," J. Soc. Issues, vol. 58, no. 3, pp. 597-615, 2002.

[12] J. Crocker, A. Karpinski, D. M. Quinn, and S. K. Chase, "When Grades Determine Self-Worth: Consequences of Contingent Self-Worth for Male and Female Engineering and Psychology Majors.," J. Pers. Soc. Psychol., vol. 85, no. 3, pp. 507-516, 2003.

[13] J. Crocker, S. R. Sommers, and R. K. Luhtanen, "Hopes Dashed and Dreams Fulfilled: Contingencies of Self-Worth and Graduate School Admissions," Personal. Soc. Psychol. Bull., vol. 28, no. 9, pp. 12751286, 2002.

[14] M. Dittmann, "Self-esteem based on external sources has mental health consequences," Monit. Psychol., vol. 33 , no. 11 , p. 16, 2002.

[15] E. L. Deci and R. M. Ryan, "The 'What' and 'Why' of goal pursuits: Human needs and the delfdetermination of behavior," Psychol. Inq., vol. 11, no. 4, pp. 227-268, 2000.

[16] M. H. Kernis, "Measuring self-esteem in context: The importance of stability of self-esteem in psychological functioning," J. Pers., vol. 73, no. 6, pp. 1569-1605, 2005.

[17] M. H. Kernis et al., "Multiple Facets of Self-Esteem and their Relations to Depressive Symptoms," Personal. Soc. Psychol. Bull., vol. 24, no. 6, pp. 657668, Jun. 1998.

[18] J. E. Roberts and I. H. Gotlib, "Temporal variability in global self-esteem and specific self-evaluation as prospective predictors of emotional distress: Specificity in predictors and outcome.," J. Abnorm. Psychol., vol. 106, no. 4, pp. 521-529, 1997.

[19] J. Crocker and L. E. Park, "Seeking self-esteem: Construction, maintenance, and protection of self- 
worth.," in Handbook of self and identity., New York, NY, US: Guilford Press, 2003, pp. 291-313.

[20] Canadian Engineering Accreditation Board, "2017 Accreditation Criteria and Procedures," 2017.

[21] A. Hutchins, "Are universities doing enough to support mental health? - Macleans.ca," MacLean's, 2017. [Online].

Available: http://www.macleans.ca/education/depth-of-despair/. [Accessed: 25-Dec-2017].

[22] Queen's University, "Student Mental Health and Wellness Report of the Principal's Commission on Mental Health," pp. 1-12, 2012.

[23] A. Bayarsaikhan, S. Services, E. U. S. Mental, H. Committee, C. Lina, and D. Genova, "McGill Engineering Undergraduate Society Wellness Survey," no. February 2017.

[24] A. P. Association, A. P. Association, M. Of, and M. Disorders, Diagnostic and Statistical Manual of Mental Disorders. 2013.

[25] Q. Golsteyn, D. S. Nino Sua, G. Fung-Quon, C. Yuen, J. Farrow, and C. Ruigrok, "An Analysis on the State of Wellness of Engineering Undergraduate Students," in Canadian Engineering Education Association Annual Meeting, 2018, p. Paper 151.

[26] University of British Columbia Vice President Students Office, "Undergraduate Experience Survey (Faculty of Applied Science Data).” 2016.

[27] P. Rosenbaum and R. D. Weatherford, "Resilience in college students," J. College Stud. Psychother., vol. 31, no. 2, pp. 91-92, 2017
P. Rosenbaum and R. D. Weatherford, "Resilience in
College Students," J. College Stud. Psychother., vol. 31, no. 2, pp. 91-92, 2017.

[29] N. Hall and D. Webb, "Instructors' Support of Student Autonomy in an Introductory Physics Course," Phys. Rev. Spec. Top. - Phys. Educ. Res., vol. 10, no. 2, pp. $1-22,2014$.

[30] M. Vansteenkiste, J. Simons, W. Lens, K. M. Sheldon, and E. L. Deci, "Motivating learning, performance, and persistence: The synergistic effects of intrinsic goal contents and autonomy-supportive contexts," J. Pers. Soc. Psychol., vol. 87, no. 2, pp. 246-260, 2004.

[31] J. Reeve and H. Jang, "What teachers say and do to support students' autonomy during a learning activity," J. Educ. Psychol., vol. 98, no. 1, pp. 209-218, 2006.

[32] S. E. Cross and N. V. Vick, "The interdependent selfconstrual and social support: The case of persistence in engineering," Personal. Soc. Psychol. Bull., vol. 27, no. 7, pp. 820-832, 2001.

[33] L. J. Friedlander, G. J. Reid, N. Shupak, and R. Cribbie, "Social Support, Self-Esteem, and Stress as Predictors of Adjustment to University Among FirstYear Undergraduates," J. Coll. Stud. Dev., vol. 48, no. 3, pp. 259-274, 2007.

[34] R. E. Thayer, "Do low grades cause college students to give up?," J. Exp. Educ., vol. 41, no. 3, pp. 71-73, 1973.

[35] J. Brockner and A. J. B. Hulton, "How to reverse the vicious cycle of low self-esteem: The importance of attentional focus," J. Exp. Soc. Psychol., vol. 14, no. 6, pp. 564-578, 1978. 